\title{
The Relation of Personality Dimension with Nationalism Consumption Level of the Sanandaj Citizens
}

\author{
Kumars Ahmadi ${ }^{a}$, Fatemeh Rahimi ${ }^{\mathrm{b}}$ \\ Department of Business Management, Islamic Azad University, Sanandaj Branch, Sanandaj, Iran \\ a,b E-mail address: ahmadi1218@yahoo.com , rahimik1979@gmail.com
}

\begin{abstract}
The purpose of this research is to determine the level of the Sanandaj citizens' personality dimensions and property relation with the nationalism consumption in 2004. The method of this study is descriptive and correlation kind. The statistic society of the current study consisted of Sanandaj people with the cognitive population property (education and economy situation) that according to the over 2000 persons of population density, 384 persons was chosen based on the Korjesi and Morgan with the classification method as the statistic objects. The information collective tool included the five personality factors questionnaire and the nationalism consumption measurement. For analysis the data, the SPSS statistic software, and for surveying the relation of the criterion and foresight variables, the analysis of the Regression and Variance correlation coefficients was used. The Regression analysis represented that the personality variable dimensions, predict the nationalism consumption variable variance at 5 percent level. This coefficient was having a positive effect in extroversion dimension, it means that with the extroversion level increment, the nationalism consumption will also increase, but in other dimensions (Excitement stability, flexibility, deontology, amiability), it had negative coefficient effect thus with any dimensions increment (Excitement stability, flexibility, deontology, amiability), the nationalism consumption level decrease.
\end{abstract}

Keywords: Nationalism Consumption; the Fivefold Personality Dimension; Economy Position; Educational Position

\section{INTRODUCTION}

In the international marketing studies about consumers' point of view to the internal and external production and their thought way about shopping, there are two attitudes: the rational information processing paradigm tells that the consumers evaluate and choose their necessary products during a mental process and based on the cognitive components effect (Batman, 2008).

Another attitude is the affective information processing paradigm; it tells that the consumers' choice is based on the emotional factors effect. In the choice field between the internal and external productions, the cognitive factors can be consisting of quality, price, accessibility level, the after sold services and the spare pieces of the internal productions can cause an orientation to the internal productions. But the factors like the normalized and moral objection to the external production shopping because of the loyalty and fondness felling to the mother country, are the emotional factors that can lead to a preference to the internal and external productions. 
For example, some of the consumers believe that external goods shopping cause the job opportunity decrement, and because it has a negative effect on the country's national economy, so it's unlike the patriotism and these productions buyers are responsible for the moral compatriots' unemployment of those who lost their job by the effect of international competition. Tendency to the internal production shopping that for the first time was considered as "The Nationalism Consumption" by the Shimp and Sharma, can affect the cognitive factors (Shimp and Sharma, 1987).

In the other hands, it caused that the nationalism consumers evaluate the internal productions more desirable than the external productions from the cognitive aspects and in the comparison with the consumers without nationalism feelings; they have a more tendency to buy the internal productions. The nationalism consumption conception is a decision making range and the subset of "nationalism" and "the economic nationalism". Sharma et al edited the nationalism consumption as "the specific range of nationalism, for consumers' behavior study to the marketing functions" (Shimp and Sharma, 1987).

The nationalism consumption is considered as the single form of the economic nationalism that indicate the consumers' feelings about the falsity and actually immortality of external productions shopping (Shimp and Sharma, 1987). In our country, the producing support policy and internal goods consumption is always at the priority of the economic and commercial policy, and one of the popular methods in the field of internal goods consumption encouragement, utilization and incense the patriotic feeling and lead these feelings to the internal goods consumption.

But despite the emphasize on the nationalism feelings role in the internal goods consumption, these orientations and causes wasn't measured and evaluated scientifically and coherently so far, and apparently the programming in this field was based on the unscientific evidences and roles. This do that in the most of the others countries, a lot of studies was done in the field of nationalism feelings role in the internal production consumption and shopping, the direct and indirect of its causes and the scientific and equinity evaluation of these orientations. One of the factors that can has the effect on the emotional properties, is the persons personality properties.

The national identity tool as one of the people's emotional and feeling properties is the nationalism plat that can be under the effect of the people's personality properties, these properties include: extroversion, amiability, deontology, the excitement stability or the up-todate tendency and flexibility (Ahmadian, 2011). Several theories consider the five factor model as a communication structure. In the person-among theory, the major emphasize is on the persons relations.

This model considers the personality as the fairy stable paradigm of person-among position that determines the humanity life. So the five factors model is realized as a descriptive conception. This model emphasizes on the person-among communication and personal motivations, and interprets the fivefold dimension as the person-among figures that can affect their choices and attitudes. According to the considered subject, this article tries to answer this question: Is there any relation between the Sanandaj citizens personality with their nationalism consumption? 


\section{THE THEORETICAL BASIS}

\section{1. Personality}

The conception of the personality in psychology is a normal and popular conception but at the same time, very complex and problematical. The vulgar function of the personality decreases as a desirable conception in the subjective attitude though its scientific conception is totally under the controversy (Garosi, 2001). At the current moment, this is not a single definition about the personality that is confirmed by everyone. For example, Allport (1949) was collecting and indicating 50 definitions about this matter. Some of the personality psychologists are study the biochemical and physiological aspects of human's action, and gaining advantage from the adequate methods for researching in this field. A group of personality psychologists notify the persons and their behavior, some others define the personality regarding to the properties like unconscious processing that is directly invisible and it should be deducted from behavior, and finally some psychologists define the personality just through the mutual relations of persons together and the role that they play in the society. So, the presumptive and available definition range is fluctuating from the organism innate process to the visible behavior cause by the person's correlation (Parvin and John, 2001, Kedivar and Javadi translation, 2002). We proceed to some of the represented definition about personality bellow:

Allport: Personality consists of dynamic organizing of innate person's physical- physiological organizations that determine the person's unique adaptability to the world.

Hilgard: Personality is a specific paradigm of behavior and thought ways that determine the person adaptability with the environment (Atkinson, Atkinson and Hilgard, 1983, Brahni et al translation, 1996).

Kettl: Personality is a matter that let us to predict a person doing in a specific position (Schultz \& Schultz, 1998, Seyed Mohammadi translation, 2002).

Izang: Personality is a stable and permanent system of the emotional, mental properties and the person's body physic that determine his/her adaptability with environment (Schultz \& Schultz, 1998, Seyed Mohammadi translation, 2002).

\section{1. 1. The Personality Dimension in Five Factors Model}

\section{Extroversion:}

The extroverts divert their interest and energy to the external world. They like the sexual stimulation and also persuasion, and tend to be cheerful (Makkrey and Kasta, 2003). The extroversion factor consists of the qualities like chattiness, courageousness and the activity level with the qualities like pipe down and hast reception.

\section{Amiability:}

Like extroversion, amiability is a dimension of person-among tendency; the amiable persons have a tendency to person-among feeling and support. The adverse axis of gracious is objection; these people are without correlation (Having some feelings about each other) and stubborn (Makkrey and Kasta, 2003). This factor consists of qualities like kindness, trust, and warm with qualities like hostility, egoism and lake of confidence (Goldberg, 1993, quotation from Ahmadian, Hamze, 2011). 


\section{Deontology (loyalty):}

The dutiful persons are full of energy, ambitious and hardworking people. They despite the available obstacles pressing on their elimination, tend to accuracy and complement. The deontology is usually connected with hardworking and physical sufficiency. The people without deontology avoid from the more essential subtlety, accuracy and cleanliness. This factor consists of the qualities like organizing, accuracy and trust worthy, (in adverse axis) with the qualities like inaccuracy, insouciance and unreliability (Goldberg, 1993, quotation from Ahmadian, Hamze, 2011).

\section{The Excitement Stability or Up to Date Orientation:}

The most effective territory of personality meters are adaptability mutuality or excitement stability or disagreement or up to date orientation (Makkrey and Kasta, 2003). This factor consists of qualities like anxiety, paralysis and freaky (Goldberg, 1993, quotation from Ahmadian, Hamze, 2011).

\section{Flexibility:}

The flexibility elements like active imagination, the beauty feeling and diversity often play a role in the personality theories and evaluation but their reunion in the large range and making. Personality factor are hardly considered. The flexible people are curious about both, the inner and the external world, and their life is rich from the experimental aspect (Makkrey and Kasta, 2003). This factor consists of qualities like imagination, curiosity and creativeness and in adverse axis, the qualities like unreason and witlessness (Goldberg, 1993, quotation from Ahmadian, Hamze, 2011).

\section{2. Nationalism Consumption}

Race and nationality are the most important factors that make each person's identity. The ethnocentric implies on the human's mutual willing for considering their own group as the center of the world, interpreting others social units with this function and negate the persons that are socially heterogeneous (Mowen and Minor, Abbas Saleh Ardastani translation, 1384). From the Sumner's point of view, in ethnocentric, people believe that their groups are at the center of the matters and other matters are measured and evaluated in the comparison with their groups. In this attitude, the members of the group honor to their group and try to show their preference to the others. In this condition, the members of the group look down to the other persons out of the group. And extremely support their traditions, visual symbols and the other production that is related to the group (Nguyen; Nguyen and Barrett, 2008). The study in this field of ethnocentric in the 1970 entered the new arena as a social basis. It determined that the people in a specific group have a better behavior with their own group members in the comparison with the other groups' members (Nguyen; Nguyen and Barrett, 2008).

During the later years, the economists attention to the nationalism role in consumers behavior, lead to the nationalism theory in the consumption formation, so the ethnocentric conception in the economic zone, enter this major as the nationalism consumption with the aim of surveying the consumers behavior factors and starting its activity as a expertise zone and a subset of nationalism economic nationalism. In this field, Zajonce and Markus (1982) and Peterson et al (1986) show that the patriotic reactions to the internal goods can powerfully transform into the emotional reactions in the consumers. With the several accomplished researches in this field, Shimp and Sharma are known as the inventor of the nationalism theory. They succeeded in the 1987 that for the first time entered the nationalism consumption practically to the researches zone and with representing the measurement scale in this range, 
making the positive steps in declaring this range to the scientific society. According to the Shimp viewpoint, the nationalism conception is for showing the consumers believe to their own production preference but these accurate surveys do not place in the economic and scientific restriction. But they are based depending on the ethics and racial basis that in cases, can affect the cognitive factors (Shimp and Sharma, 1987).

Actually, the nationalism consumers have a positive attitude to the internal goods, these stereotypes form with ethics and normal factors, and accompany the positive evaluation of the internal good though they have crack from the cognitive aspect. Totally, in nationalism consumers' evaluation, the moral and emotional fund has dominance to the logical fund. In such condition, the nationalist consumers evaluate the internal productions more desirable than the external productions from the cognitive aspect, and in the comparison with the consumers without nationalism feelings, have more tendency to try the internal goods and regarding to the fortification of their emotional attitudes even may prefer the unqualified internal productions than the qualified external productions and the versus of this subject can be right (Watson and Rayt, 2000). Totally it should be said that the internal productions preference than the external productions, May because of the reality of the internal productions preference or may because of their accommodation of these productions with the values, norms, tastes, habits, and culture of the consumers.

Dorvasola et al (1997) enter the effective variable to the nationalism consumption that collimates the nationalism consumption fear relation and the attitude to the importation. This variable that includes the vitality of the goods in the daily life, because it's the consumers' life style determiner that is notified by the researches, and Sharma et al believe that whenever that the consumers make this calculation that a placed as the essential goods, it eases the external productions usage. But the nationalism may exist in the consumers mind but this matter won't affect their final action. This condition is specially being intensified when the internal productions don't be available for the consumers. So, Sharma et al (1995) describe that the consumers include both, with nationalism and without nationalism need to import some specific goods for their daily life, which it places in the vital and essential level. So, if that goods precept as the necessary goods, the nationalism feeling of the consumers play a lighter role in the attitude toward that productions preparation.

\section{RESEARCH METHOD}

As the purpose of this study is to determine the dimensions relation level and the Sanandaj Citizens personality qualities with their nationalism consumption level, so according to the aim, the current study is a practical study and depend on the performance, it's one of the descriptive kind of researches. So according to this, the statistic society of the study consists of the Sanandaj's people regarding to their population position (education and economic position).

For calculating the object mass in this research, the Korjesi and Morgan model was used and based on this model, if the statistic society be more than 2000 persons, the 384 persons are adequate as the object mass. So the statistic objects of this research are 384 persons of Sanandaj citizens. In the current study, regarding to the research subject identity and the studied statistic society, the straticulate sampling is proportionally used. 


\section{RESULTS}

- Assumption: The Sanandaj citizens' personality qualities and dimensions have a relation with their nationalism consumption level.

- The correlation test: For surveying the relation of the Sanandaj citizens' personality dimensions and qualities with their nationalism consumption, and regarding to the variable scale kind, the Pearson correlation test is used. The epenthetic results in the Table (1) show that there is a positive and meaningful relation at one percent level between the Sanandaj citizens' personality qualities and dimensions with their nationalism consumption. Also, for surveying the level of the dependence variable dimensions effect the regression test is used.

Table 1. The Relation of Sanandaj Citizens' Personality Qualities and Dimensions with the Nationalism Consumption Level.

\begin{tabular}{|c|c|c|c|}
\hline The coincidental variable & $\begin{array}{c}\text { The correlation } \\
\text { coefficient kind }\end{array}$ & $\begin{array}{c}\text { The correlation } \\
\text { coefficient }\end{array}$ & $\begin{array}{c}\text { The meaningfully } \\
\text { level }\end{array}$ \\
\hline $\begin{array}{c}\text { The personality qualities } \\
\text { and dimensions }\end{array}$ & Pearson & $* * 0 / 798$ & $0 / 000$ \\
\hline
\end{tabular}

*and** sequencely show the meaningfully level at 1 percent and 5 percent level

- The multifold regression: For surveying the effect of the studied independence variables dimensions on the dependence variables of nationalism consumption is used. The aim of real measurement is the effect of the independence variable dimensions on the dependence variable and predicting the dependence variable changes according to the any one of the independence variable dimensions.

For surveying the variable dimensions effect of the Sanandaj citizens' personality qualities and dimensions on the nationalism consumption, a series of the factors is placed and described contemporary in the Regression model. The summery of the Regression results analysis are brought in the Table (2). The analysis of the results is like that:

Table 2. The coefficient of determining the effective variable on the nationalism consumption.

\begin{tabular}{|c|c|c|c|c|c|}
\hline & Variable & $\mathrm{R}$ & $R^{2}$ & $R^{2} \mathrm{Ad}$ & $\begin{array}{c}\text { The standard error of the } \\
\text { correlation coefficient }\end{array}$ \\
\hline 1 & $\begin{array}{c}\text { The personality } \\
\text { qualities and } \\
\text { dimensions }\end{array}$ & $0 / 792$ & $0 / 627$ & $0 / 623$ & $4 / 29145$ \\
\hline
\end{tabular}

- With looking at the achieved model of the study, it's observed that the combinational correlation level increase this multifold correlation coefficient variable to $0 / 792$ and also the determining coefficient to $0 / 627$ of the Sanandaj citizens' personality qualities and dimensions on the nationalism consumption.

Actually, the Sanandaj citizens' personality qualities variable that is $0 / 623$ is specifying from the nationalism consumption changes. 
Table 3. The variance analysis of the Sanandaj citizens' personality qualities and dimensions on the nationalism consumption level.

\begin{tabular}{|c|c|c|c|c|c|}
\hline Model & $\begin{array}{c}\text { The quadrates } \\
\text { collection }\end{array}$ & $\begin{array}{c}\text { Freedom } \\
\text { degrees }\end{array}$ & $\begin{array}{c}\text { The quadrate } \\
\text { average }\end{array}$ & F & Meaningfully \\
\hline Regression 1 & $11723 / 473$ & 5 & $2344 / 659$ & $127 / 314$ & $0 / 000$ \\
\hline Remainder & $6961 / 462$ & 378 & $18 / 417$ & & \\
\hline Total & $18684 / 935$ & 383 & & & \\
\hline
\end{tabular}

- The results of Table (3) hold out the meaningfully of the Regression model that the F calculated amount is $127 / 314$ with the 5 and 378 freedom degrees that is bigger than the table amount and the meaningfully of the Regression model. So the zero assumption is based on the refusal the lack of relation between the Sanandaj citizens' personality qualities with nationalism consumption and the substantiative assumption that confirm this (fact).

Regarding to the meaningfully of the Regression, the personality qualities components with nationalism consumption level, the related coefficients with the predicted equation are brought in the Table (4).

Table 4. The effect level of the personality qualities variables with the nationalism consumption level.

\begin{tabular}{|c|c|c|c|c|}
\hline Variable & $\mathrm{B}$ & Beta coefficient & $\mathrm{T}$ & $\mathrm{Sig}$ \\
\hline The fixed coefficient: b0 & $103 / 498$ & & $17 / 309$ & $0 / 000$ \\
\hline The excitement stability & $-0 / 241$ & $0 / 244$ & $-4 / 807$ & $0 / 000$ \\
\hline Flexibility & $-1 / 090$ & $0 / 725$ & $-15 / 018$ & $0 / 000$ \\
\hline Deontology & $-0 / 605$ & $0 / 259$ & $-6 / 895$ & $0 / 000$ \\
\hline Amiability & $-0 / 171$ & $0 / 084$ & $-2 / 155$ & $0 / 032$ \\
\hline Extroversion & $0 / 723$ & $0 / 338$ & $8 / 184$ & $0 / 000$ \\
\hline
\end{tabular}

The above table is surveying the Regression variables that regarding to the table results, the observed Beta amount for the excitement stability, flexibility, deontology, amiability and extroversion variables are sequencely $(0 / 0,0 / 244,0 / 725,0 / 259,338 / 084)$, it means that with one score changing in the personality dimensions variables amount (The excitement stability, flexibility, deontology, amiability, extroversion), the dependence variable is changing into $(0 / 0,0 / 244,0 / 725,0 / 259,338 / 084)$ that this amount is meaningful at the $0 / 05$ level.

Regarding to the results, the Regression model is like the following form:

The Nationalism Consumption $=$ the excitement stability $*(-0 / 241)+$ flexibility $*(-1 / 090)+$ deontology $*(-0 / 605)+$ amiability $*(-0 / 171)+$ extroversion $*(0 / 723)+(103 / 498)$ 


\section{DISCUSSION ABOUT RESULTS (CONCLUSION)}

The aim of this article is to determine the relation level of the Sanandaj citizens' personality qualities and dimensions with the nationalism consumption. According to the results, the combinational correlation level of the independence variables effect of the Sanandaj citizens' personality qualities on the nationalism consumption level shows that this variable increased the multifold correlation coefficient to 0/792 and the determining coefficient to 0/627. Actually the variable are separating the Sanandaj citizens' personality qualities from the nationalism consumption changings or in other hands, there is a meaningful relation (connection) between these two variables. What the achieved results of this study hold out that the results of this study has directly and indirectly similar relation with the researches of; Lee et al (2005), with this topic "survey the consumption reaction of these three country, Japan, South Korea and Mexico to the American productions; Dosen et al (2007), with the topic "comparison of the external productions tendency and about a group of nutrients; Komar (2009), with this topic "survey the productions subjective and specific variables on the American goods shopping intention in the Netherlands, and the researches of Haghighi and Hasanzade (2008), with this topic "the comparison of the internal good consumption tendency level in Tehran with other regions of the world and survey its consequences on the productions evaluation and tendency.

\section{References}

[1] Ahmadian H., The edition and testing the model of the relation between the five great personality factors, the basis psychical and psychology welfare, Ph.D. rescript, Islamic Azad University, Tehran science and researches unit 15(2) (2011) 84-91.

[2] Moon J., Minor M., The consumer behavior (external factors) (Abbas Saleh Ardastani translation). Tehran: Farabi (2005).

[3] Haghighi M., Hosseinzade M., The comparison of the internal good consumption tendency level in Tehran with other regions of the world and survey its consequences on the productions evaluation and tendency, The researches management magazine in Iran, course 13(4) (2009) 103- 139.

[4] Bahmani M., Survey the nationalism consumption level, trust to advertisings and the orientation to internal goods consumption between 28 cities citizens (2012).

[5] Sholtez D., Sholtez S.D., The personality theories, Yahiya Seyed Mohammadi translation, Tehran: Edition (2002).

[6] Atkinson R., Atkinson R, S., Hilgard A, R., The psychology field (1), Mohammad Taghee Brahni et al translation, Tehran: Roshd (1996).

[7] Parvin LI., John OB., Personality: theory and research, Mohammad Jafar Javadi and Parvin Kodivar translation, Tehran: Ayyej (2002).

[8] Shimp T. \& Sharma S., Consumer Ethnocentrism: Construction and Validation of the Cetscale. Journal of Marketing Research, 24 (1987).

[9] Nguyen T.D., Nguyen T.M., Barrett N.J., Consumer Ethnocentrism, Cultural Sensitivity, and Intention to Purchase Local products-Evidence from Vietnam. Journal of Consumer Behavior 7 (2008) 88-100. 
[10] Watson J.J., \& Wright K., Consumer Ethnocentrism and attitudes Toward Domestic and Foreign Products. European Journal of Marketing 34 (2006) 9-10.

[11] Kumar A., Hyun-Joo L., Youn-Kyung K., Indian consumers' purchase intention toward a United States versus local brand", Journal of Business Research, 62 (2009) 521-527.

[12] Dusen A., Roderick J., The influence of brand image and company reputation where manufacturers market to small firms: A customer value perspective", Industrial Marketing Management 36 (2007) 230-240.

[13] Lee M., Youn-Kyung K., \& Ann Fair H.,Shopping value in online auctions: Their antecedents and outcomes ", Journal of Retailing and Consumer Services 16 (2005) 75-82.

[14] Hackley C., Advertising and Promotion, Communicating Brands. London: Sage. Javalgi R.G., Khare V.P., Scherer R.F,. An Application of the Consumer Ethnocentrism Model to French Consumers. International Business Review 14 (2005) 325-344.

[15] Sharma S., Shimp T.A., Shin J., Consumer Ethnocentrism: A Test of Antecedents and Moderators. Journal of The Academy of marketing Science, 23(1) (1995) 26-37. 